\title{
Cell Growth Inhibition by Membrane-Active Components in Brownish Scale of Onion
}

\author{
Miyuki Furusawa, ${ }^{a}$ Hironori Tsuchiya, ${ }^{b}$ Motohiko Nagayama, ${ }^{b}$ Toshiyuki Tanaka, ${ }^{*, c}$ \\ Masayoshi Oyama, ${ }^{c}$ Tetsuro Ito, ${ }^{a}$ Munekazu Iinuma, ${ }^{c}$ and Hiroshi Takeuchi ${ }^{b}$ \\ ${ }^{a}$ Gifu Prefectural Institute of Health and Environmental Sciences, 1-1 Naka Fudogaoka, Kakamigahara, Gifu 504-0838, Japan, ${ }^{b}$ Asahi \\ University School of Dentistry, 1851-1 Hozumi, Mizuho, Gifu 501-0296, Japan, and ' Gifu Pharmaceutical University, 5-6-1 Mitahora- \\ higashi, Gifu 502-8585, Japan
}

(Received May 8, 2006; Accepted July 26, 2006; Published online August 8, 2006)

\begin{abstract}
The growth-inhibitory effects of the brownish scale components of onion on tumor cells were studied with relating to their membrane activity. Quercetin, quercetin-4'-O-glucoside and two isomeric quercetin dimers (10 $\mu \mathrm{M}$ for each) isolated from the scale reduced the fluidity of tumor cell model membranes consisting of phospholipids and cholesterol more significantly than that of normal cell model membranes. In flavonoidal components, the membrane activity was greatest in the order of dimers, aglycone and glucoside. Quercetin and its dimers intensively acted on the membrane center rather than the membrane surface, while quercetin-4'-O-glucoside was relatively effective on the hydrophilic regions of membranes. Membrane-active flavonoids inhibited the growth of mouse myeloma cells at 10-100 $\mu \mathrm{M}$ with the same rank of order of potency as they rigidified liposomal membranes. Quercetin and its dimers rigidified cell membranes by acting on the hydrophobic inner regions simultaneously with inhibiting the cell growth, but not quercetin-4'-O-glucoside. Flavonoidal components in the brownish scale of onion have the potent anti-proliferative activity associated with the structure-specific rigidification of cell membranes, which is induced by the interaction with membrane lipid bilayers.
\end{abstract}

Key words — onion, brownish scale, flavonoidal components, cell growth inhibition, membrane fluidity change

\section{INTRODUCTION}

Foods and beverages have been widely recognized to possess medicinal (preventive and therapeutic) and/or toxic properties besides their nutritional and tasting significance. In particular, foods of plant origin or vegetative foods are referred to as the major source for bioactive compounds with the ability to inhibit various stages of tumor development. ${ }^{1)}$ The search for functional food phytochemicals and the understanding of their mode of action have been so far performed by focusing on the suppression of abnormal cell proliferation, the inhibition of carcinogen activation, the scavenging of DNA and RNA reactive agents, the promotion of anti-oxidation, the induction of apoptosis, the modification of critical enzyme activity, etc. ${ }^{2,3)}$ In addition to these traditional strategies, recent studies suggest a new concept that plasma membranes and membraneous organelles may be the promising tar-

\footnotetext{
*To whom correspondence should be addressed: Gifu Pharmaceutical University, 5-6-1 Mitahora-higashi, Gifu 502-8585, Japan. Tel.: +81-58-237-3931; Fax: +81-58-237-5844; E-mail: ttanaka@gifu-pu.ac.jp
}

gets for anti-tumor action. ${ }^{4,5)}$

Almost all of tumor cells show different membrane fluidity from their normal counterparts ${ }^{6)}$ and the increased fluidity of cell membranes is related to the proliferative and metastatic activity. ${ }^{7,8)} \mathrm{Sev}$ eral anti-tumor food components interact with biomembranes, including liposomal, cellular and mitochondrial membranes, to alter their physicochemical properties as well as chemopreventive and cytotoxic drugs. ${ }^{9-12)}$ The active phytochemicals isolated from such foodstuffs as green tea, soybean, grape and their products influence cell growth by modifying membrane fluidity. ${ }^{13,14)}$ The interaction with membrane lipid bilayers also can be an index for screening the potent bioactivity of plant foods. ${ }^{15)}$

Flavonoids have been most frequently studied because of their widespread occurrence in plant foods and the diversity of the mode of action. ${ }^{16)}$ Onion (Allium cepa) is one of the representative plant foods rich in flavonoids. Phytochemical researches have exclusively dealt with its edible inner bulb to reveal the content and bioactivity of flavonoidal components. ${ }^{17)}$ In a recent study, however, the inedible brownish scale was found to contain character- 
<smiles>O=c1c(O)c(-c2ccc(O)c(O)c2)oc2cc(O)cc(O)c12</smiles>

Quercetin (Q)<smiles>CC(C)(C)Oc1ccc(-c2oc3cc(O)cc(O)c3c(=O)c2O)cc1O</smiles>

Quercetin-4'-O-glucoside (QG)<smiles>O=C1c2c(O)cc(O)cc2OC2(c3ccc(O)c(O)c3)Oc3ccc(-c4oc5cc(O)cc(O)c5c(=O)c4O)cc3OC12O</smiles>

Quercetin dimer-1 (QD-1)<smiles>O=C1c2cc(O)cc(O)c2OC2(c3ccc(O)c(O)c3)Oc3cc(-c4oc5cc(O)cc(O)c5c(=O)c4O)ccc3OC12O</smiles>

Quercetin dimer-2 (QD-2)

Fig. 1. Structures of Flavonoids Isolated from Brownish Scale of Onion

istic flavonoids which were structurally identified as glycosylated and dimerized derivatives of quercetin (Q). ${ }^{18)}$ Such components inhibited human platelet aggregation and dissociated platelet aggregates, and the interaction with membrane lipids was suggested as a possible mechanistic basis for their antiaggregatory and disaggregatory effects. ${ }^{19)}$ Membrane perturbation is also known to be responsible for not only platelet aggregation inhibition ${ }^{20,21)}$ but cell growth inhibition by drugs and food components. ${ }^{5,15}$

In the present study, we aimed to clarify the antiproliferative activity of the brownish scale of onion by determining the cell growth-inhibitory effects of flavonoidal components associated with membrane fluidity changes.

\section{MATERIALS AND METHODS}

Chemicals Phospholipids: 1-palmitoyl-2oleoylphosphatidylcholine (POPC), 1,2-dipalmitoylphosphatidylcholine (DPPC), 1-palmitoyl-2oleoylphosphatidylethanolamine (POPE) and 1stearoyl-2-oleoylphosphatidylserine (SOPS) were purchased from Avanti Polar Lipids (Birmingham, AL, U.S.A.), and cholesterol from Wako Pure Chemicals (Osaka, Japan). Fluorescence probes: 2(9-anthroyloxy)stearic acid (2-AS), 6-(9anthroyloxy)stearic acid (6-AS), 9-(9anthroyloxy)stearic acid (9-AS), 12-(9- anthroyloxy)stearic acid (12-AS), 16-(9anthroyloxy)palmitic acid (16-AP) and 1,6-diphenyl-1,3,5-hexatriene (DPH) were obtained from Molecular Probes (Eugene, OR, U.S.A.). Dimethyl sulfoxide (DMSO) of spectroscopic grade (Kishida, Osaka, Japan) was used for dissolving the tested compounds. All other reagents were of the highest analytical grade available.

Onion Scale Components _— Flavonoidal components were isolated as reported previously. ${ }^{18,19)} \mathrm{In}$ brief, the brownish scale of onion obtained from commercial outlets was air-dried, powdered and extracted with methanol, followed by three-step chromatographic purifications. Based on spectral data, the finally obtained isolates were identified as $\mathrm{Q}$, quercetin-4'-O-glucoside (QG) and two isomeric quercetin dimers (QD-1 and QD-2) (Fig. 1).

Cell Model Membrane _ Liposomes with the lipid bilayer structure were prepared by the method of Tsuchiya et al..$^{22)}$ with some modifications as follows. The dry film consisting of POPC, POPE, SOPS and cholesterol $(48: 24: 8: 20, \mathrm{~mol} \%)$, which was comparable to the lipid composition of tumor cell membranes, ${ }^{23)}$ was dissolved with methanol so that the total lipid concentration was $10 \mathrm{mM}$. An aliquot $(0.25 \mathrm{ml})$ of the methanol solution was injected four times into $199 \mathrm{ml}$ of Dulbecco's phosphate-buffered saline (PBS, pH 7.4; Dainippon Pharmaceuticals, Osaka, Japan) at $55^{\circ} \mathrm{C}$ under stirring, and then gentle vortexing was carried out for $1 \mathrm{~min}$. With this pro- 
Table 1. Effects of Flavonoids on Liposomal Membranes

\begin{tabular}{lccccc}
\hline \hline & \multicolumn{5}{c}{ Polarization change from control } \\
\cline { 2 - 6 } Flavonoid & 2-AS & 6-AS & 9 -AS & $12-\mathrm{AS}$ & $16-\mathrm{AP}$ \\
\hline Q & $0.0358 \pm 0.0006^{* *}$ & $0.0444 \pm 0.0007^{* *}$ & $0.0446 \pm 0.0014^{* *}$ & $0.0457 \pm 0.0006^{* *}$ & $0.0264 \pm 0.0008^{* *}$ \\
QG & $0.0104 \pm 0.0009^{* *}$ & $0.0080 \pm 0.0009^{* *}$ & $0.0077 \pm 0.0008^{* *}$ & $0.0087 \pm 0.0011^{* *}$ & $0.0066 \pm 0.0007^{* *}$ \\
QD-1 & $0.0680 \pm 0.0009^{* *}$ & $0.0792 \pm 0.0011^{* *}$ & $0.0905 \pm 0.0009^{* *}$ & $0.1024 \pm 0.0011^{* *}$ & $0.0860 \pm 0.0022^{* *}$ \\
QD-2 & $0.0460 \pm 0.0008^{* *}$ & $0.0552 \pm 0.0009^{* *}$ & $0.0594 \pm 0.0007^{* *}$ & $0.0648 \pm 0.0008^{* *}$ & $0.0461 \pm 0.0005^{* *}$ \\
\hline \multicolumn{5}{r}{ After liposomes were treated with flavonoids at $10 \mu \mathrm{M}$ for each, membrane fluidity changes were determined by measuring fluorescence } \\
polarization. Mean \pm SEM $(n=7) . * * p 0.01$ compared with control.
\end{tabular}

cedure, unilamellar vesicles were prepared. ${ }^{24)}$ Liposomes with different lipid composition were also prepared by mixing cholesterol, POPC and DPPC so that the cholesterol content was either 20 or $40 \mathrm{~mol} \%$ and the phosphatidylcholine acyl chain $18: 1 / 16: 0$ ratio $(18: 1 / 16: 0)$ was either 1.0 or 0.5 .

\section{Membrane Fluidity Change — The DMSO so-} lutions of Q, QG, QD-1 and QD-2 were added to liposomal suspensions to give a final concentration of $10 \mu \mathrm{M}$ for each, followed by incubation at $37^{\circ} \mathrm{C}$ for $30 \mathrm{~min}$. DMSO was added to the corresponding controls. After addition of the acetone solution of 2AS, 6-AS, 9-AS, 12-AS and 16-AP (final concentration: $0.5 \mu \mathrm{M}$ for each) or DPH $(1.25 \mu \mathrm{M})$, the suspensions were incubated at $37^{\circ} \mathrm{C}$ for $1.5 \mathrm{hr}$ to label liposomes with $n$-AS and 16-AP or for $0.5 \mathrm{hr}$ with $\mathrm{DPH}$. The concentrations of DMSO and acetone were adjusted to be less than $0.5 \%(\mathrm{v} / \mathrm{v})$ in the total volume so as not to influence the fluidity of liposomal membranes. Fluorescence polarization was measured by an RF-540 spectrofluorometer (Shimadzu, Kyoto, Japan) equipped with a polarizer and a cuvette controlled at $37^{\circ} \mathrm{C}$ under conditions reported previously. ${ }^{25,26)}$ Compared with controls, an increase of polarization means the reduction of membrane fluidity, membrane rigidification. ${ }^{14,19)}$

Cell Culture — Mouse myeloma cells ( $\mathrm{Sp} 2 / 0$ Ag14) were cultured in Dulbecco's modified Eagle's medium (ICN Biomedicals, Aurora, OH, U.S.A.) supplemented with $10 \%(\mathrm{v} / \mathrm{v})$ fetal bovine serum (Gibco Life Technologies, Rockville, MD, U.S.A.) at $37^{\circ} \mathrm{C}$ in a humidified $5 \% \mathrm{CO}_{2}$ atmosphere. Cells in the exponential growth phase were harvested and seeded at $2.5 \times 10^{5}$ cells $/ \mathrm{ml}$ of medium in $35-\mathrm{mm}$ diameter dishes. They were incubated after addition of the DMSO solutions of Q, QG, QD-1 and QD-2 at 10 and $100 \mu \mathrm{M}$. An appropriate volume $(0.5 \%, \mathrm{v} /$ v) of DMSO vehicle was added to the corresponding controls. After 24 and $48 \mathrm{hr}$, the number of viable cells was counted by a hemocytometer as re- ported previously. ${ }^{14)}$

An aliquot $(2 \mathrm{ml})$ of cell cultures was collected after incubation for 1-48 hr. The cells were washed twice with PBS, and then resuspended in PBS at 5.0 $\times 10^{4}$ cells $/ \mathrm{ml}$. They were labeled with DPH, 2-AS or 12 -AS (1.0 $\mu \mathrm{M}$ for each) as described above. After removal of the excess free probes by washing with PBS, fluorescence polarization of the cell suspensions in PBS was measured as described above. Statistical Analysis _ All data are expressed as means $\pm \operatorname{SEM}(n=7-10$ for liposomal membrane experiments and $n=5$ for cell culture experiments). Statistical comparison was performed by Student's $t$-test and values of $p<0.01$ were considered significant.

\section{RESULTS}

Brownish scale components interacted with lipid bilayers to rigidify liposomal membranes at $10 \mu \mathrm{M}$ as shown by $n$-AS and 16-AP polarization increases (Table 1). When comparing all polarization changes, membrane rigidification was greatest in the order of QD-1, QD-2, Q and QG.

Since the fluorophores of $n$-(9-anthroyloxy) fatty acids $(n=2,6,9,12,16)$ selectively locate at a graded series of levels in lipid bilayers, fluorescence polarization reflects the fluidity gradient extending from the surface to the center of membranes with an increase of $n .^{25)} 2$-AS indicates the fluidity change just below phospholipid head groups, while 12-AS and 16-AP indicate that close to the hydrocarbon core of lipid bilayers. In comparison of the relative changes of 2-AS, 6-AS, 9-AS, 12-AS and 16-AP polarization, both $\mathrm{Q}$ and its dimers interacted with the hydrophobic inner regions of liposomal membranes more intensively than the hydrophilic outer regions (Fig. 2). Q, QD-2 and QD-1 acted on the membrane core in increasing order of intensity. Al- 


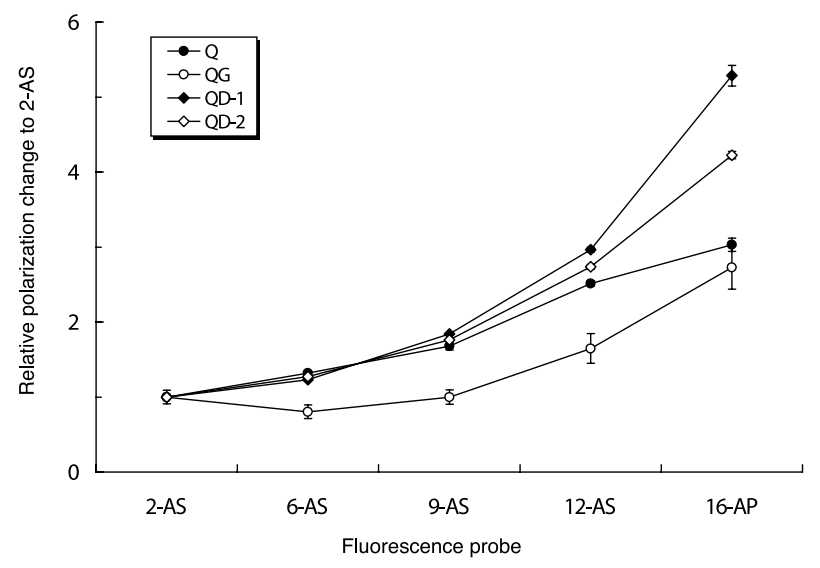

Fig. 2. Effects of Flavonoids on Different Regions of Cell Model Membranes

After treatment of liposomal membranes with Q, QG, QD-1 and QD-2 at $10 \mu \mathrm{M}$, fluorescence polarization was measured with different probes. The relative polarization changes of 6-AS, 9-AS, 12-AS and 16-AP to 2-AS were plotted (mean \pm SEM, $n=7$ ).

though QG was less effective in rigidifying membranes, it showed the relatively intensive interaction with the membrane surface unlike the other flavonoids.

Tumor cells are generally different in the membrane lipid composition from normal counterparts. The cholesterol/phospholipid molar ratio is $0.3-0.4$ and the phosphatidylcholine unsaturation degree is relatively high in the former, while being $0.6-0.7$ and relatively low in the latter. ${ }^{6,23)}$ The membranerigidifying effects were compared between tumor cell model membranes (cholesterol of $20 \mathrm{~mol} \%$ and $18: 1 / 16: 0$ of 1.0$)$ and normal cell model membranes (cholesterol of $40 \mathrm{~mol} \%$ and $18: 1 / 16: 0$ of 0.5 ) by treating with $10 \mu \mathrm{M}$ flavonoids. The rigidifying potency ratio of tumor to normal cell model membranes (mean $\pm \mathrm{SEM}, n=10$ ) was $2.16 \pm 0.13$, $2.63 \pm 0.02,2.72 \pm 0.05$ and $3.13 \pm 0.04$ for $Q G, Q$, QD-2 and QD-1, respectively.

Membrane-active flavonoids inhibited the cell growth with different potency being $\mathrm{QG}<\mathrm{Q}<\mathrm{QD}$ $2<$ QD-1 (Fig. 3). Q, QD-1 and QD-2 showed the inhibition of $57.9 \pm 5.9 \%, 94.9 \pm 2.2 \%$ and $73.3 \pm$ $4.8 \%$, respectively, by incubating at $100 \mu \mathrm{M}$ for 24 $\mathrm{hr}$. Their inhibitory effects became greater with increasing the incubation time. QG needed the incubation for $48 \mathrm{hr}$ to inhibit by $64.0 \pm 3.7 \%$. QD-1 was also effective at $10 \mu \mathrm{M}$ to produce the inhibition of $58.3 \pm 4.8 \%$ after $48 \mathrm{hr}$ incubation. However, no other flavonoids were growth-inhibitory on tumor cells at $10 \mu \mathrm{M}$. The increase of viable cells was found in the treatment with $10 \mu \mathrm{M} \mathrm{Q}$ and QG

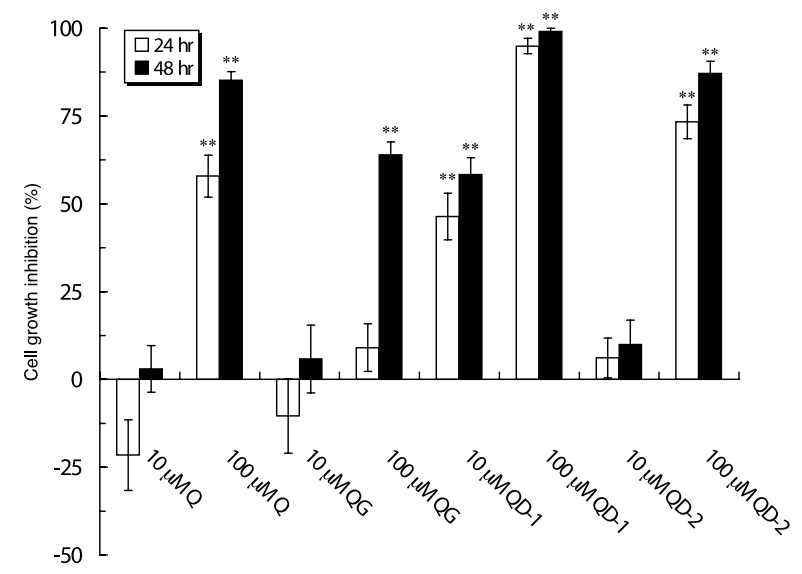

Fig. 3. Effects of Flavonoids on Cell Growth

Mouse myeloma cells $\left(2.5 \times 10^{5}\right.$ cells $\left./ \mathrm{ml}\right)$ were incubated with 10 $100 \mu \mathrm{M}$ Q, QG, QD-1 and QD-2. The cell growth inhibition was determined based on the viable cell number counted after 24 and $48 \mathrm{hr}$ (mean \pm SEM, $n=5$ ). $* * p<0.01$ compared with control.

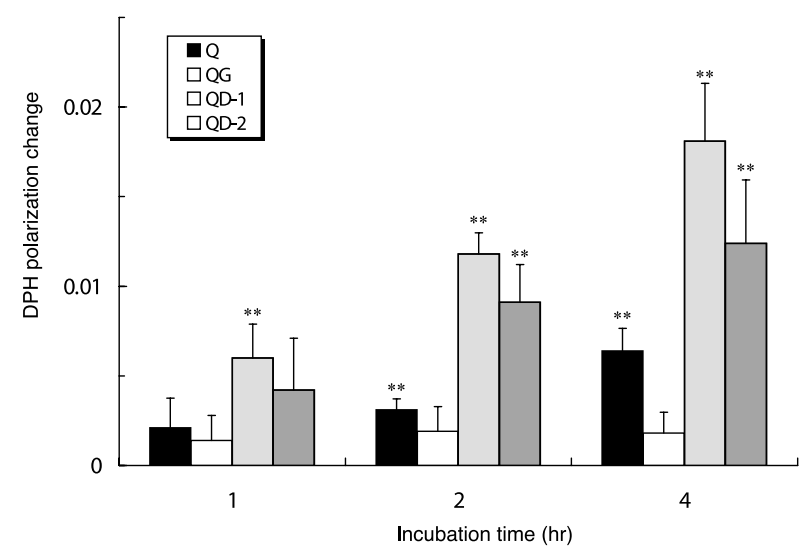

Fig. 4. Time-Dependent Effects of Flavonoids on Cell Membranes

Mouse myeloma cells $\left(2.5 \times 10^{5}\right.$ cells $\left./ \mathrm{ml}\right)$ were incubated with $100 \mu \mathrm{M} \mathrm{Q}, \mathrm{QG}, \mathrm{QD}-1$ and QD-2. The fluorescence polarization of cell membranes was measured with DPH at the indicated time (mean \pm SEM, $n=5) . * * p<0.01$ compared with control.

for $24 \mathrm{hr}$, while not being statistically significant.

The fluidity changes of cell membranes were determined after treatment with flavonoids of the concentration $100 \mu \mathrm{M}$, at which they were effective in inhibiting the cell growth. After incubation for 1$4 \mathrm{hr}$, the cells were labeled with DPH because this probe has been most widely used in cell membrane experiments and the labeling with it is completed in a relatively short time. ${ }^{9,13)} \mathrm{Q}$, QD-1 and QD-2 rigidified cell membranes with increasing the incubation time, but not QG (Fig. 4). All the flavonoids, which inhibited the cell growth inhibition after $24 \mathrm{hr}$, modi- 


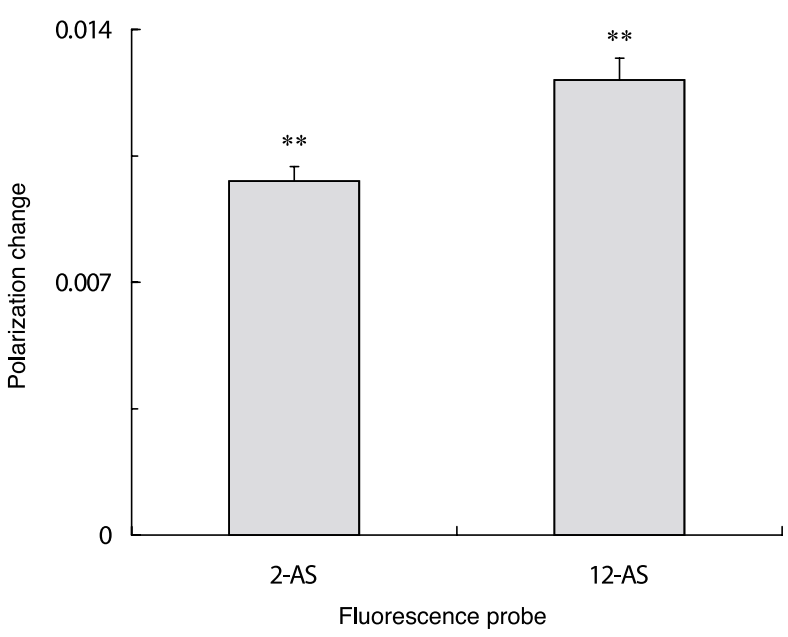

Fig. 5. Effects of QD-1 on Different Regions of Cell Membranes After incubation of mouse myeloma cells $\left(2.5 \times 10^{5} \mathrm{cells} / \mathrm{ml}\right)$ with $10 \mu \mathrm{M}$ QD-1 for $24 \mathrm{hr}$, the fluorescence polarization of cell membranes was measured with 2-AS and 12-AS (mean $\pm \operatorname{SEM}, n=5$ ). ${ }^{* *} p<0.01$ compared with control.

fied the fluidity of cell membranes immediately after incubation.

Since the DPH polarization changes suggested the time-dependent rigidification of cell membranes, the cells incubated for $24 \mathrm{hr}$ were labeled with 2-AS and 12-AS to compare the membrane-acting sites simultaneously with determining the cell growthinhibitory effects. The most potent QD-1 showed the growth inhibition of $46.4 \pm 9.6 \%$ at $10 \mu \mathrm{M}$. Comparative increases of 2-AS and 12-AS polarization indicated that QD-1 acted on the core of cell membranes more intensively than the surface (Fig. 5). Such a mode of action was similar to that on liposomal membranes.

\section{DISCUSSION}

Flavonoids contained in the brownish scale of onion interacted with lipid bilayers and changed the fluidity of liposomal membranes. With regard to the potency and site of action, QD-1 and QD-2 were more active than $\mathrm{Q}$ to rigidify the membrane hydrophobic regions. Their structure-specific effects are attributed to hydrophobicity or membrane permeability enhanced by dimerization. Unlike Q, QG was a less effective rigidifier which acted on the membrane surface as well as the membrane center. Difference between aglycone and glucoside may be produced by the presence of 4'-O-glucose which reduces the hydrophobic interaction with membrane lipid bi- layers.

Membrane-rigidifying flavonoids inhibited the growth of tumor cells at $100 \mu \mathrm{M}$ with the same rank of order of potency (QG $<\mathrm{Q}<\mathrm{QD}-2<\mathrm{QD}-1)$ as they rigidified liposomal membranes. The most membrane-active QD-1 was the cell growth inhibitor even at $10 \mu \mathrm{M}$. Such a positive correlation suggests that the ability to interact with membrane lipids is possibly linked to the anti-proliferative activity. Q characteristically decreased the number of viable mouse myeloma cells at $100 \mu \mathrm{M}$ but tended to increase at $10 \mu \mathrm{M}$. Such a biphasic effect to inhibit the cell growth at high concentrations and stimulate at low concentrations is also found in the effect of Q on human oral squamous carcinoma cells. ${ }^{14)}$

The altered physicochemical properties of plasma membranes and membraneous organelles are related to proliferation, metastasis and malignancy of tumor cells. In various types of tumor cells, the increasing unsaturation degree of phospholipid acyl chains and the decreasing ratio of cholesterol to phospholipids impart the fluidity to cell membranes. ${ }^{6,23,27)}$ The membrane-active flavonoids, especially QD-1, rigidified more fluid tumor cell model membranes more significantly than less fluid normal cell model membranes, suggesting that they may selectively act on tumor cells to influence their membrane fluidity and growth. The selectivity of flavonoid and membrane interaction is derived from the lipid composition of less cholesterol and more unsaturated phospholipids. ${ }^{14)}$ Such a mode of action appears to be advantageous for onion scale components to be the potent specific inhibitor of tumor cell growth.

As QD-1 and Q rigidified tumor cell membranes, anti-tumor or cytotoxic membrane rigidifiers restore the abnormally fluidized cell membranes. ${ }^{9,10,13,14)}$ On the other hand, membrane fluidizers act on human glioma cells to increase both the fluidity of mitochondrial membranes and the thymidine incorporation into DNA at nanomolar concentrations, ${ }^{28)}$ which are compatible with those stimulating cell growth and DNA synthesis. ${ }^{29)}$

While the membrane activity is correlated to the anti-proliferative activity, the detailed mechanistic linkage between membrane rigidification and cell growth inhibition remains unclear. The interaction with membrane lipids and resulting fluidity changes affect the conformation of membrane-bound proteins and the efficacy of biochemical reaction and signaling in cell membranes. ${ }^{5,30)}$ Membrane rigidification is responsible for the activity of membrane enzymes, receptors and channels, which is inhibited by de- 
creasing membrane fluidity. ${ }^{31)}$ The membrane-mediated mechanism also underlies the suppression of membrane lipid oxidation and the induction of apoptosis. ${ }^{32,33)}$

Q is known to show a variety of effects: antioxidative, anti-hypertensive, anti-arrhythmic, antiplatelet, anti-inflammatory, anti-microbial, antimutagenic, etc. ${ }^{16)}$ While such bioactive $\mathrm{Q}$ is commonly present as glucoside, 4'-O-glycosylation significantly decreases the bioactivity of aglycone, ${ }^{34)}$ being consistent with the present result that QG was inferior to $\mathrm{Q}$ in both membrane-rigidifying and antiproliferative activity. Although QG caused neither cell growth inhibition nor cell membrane rigidification within $24 \mathrm{hr}$ of incubation, it became effective by incubating for $48 \mathrm{hr}$. The sufficient deglycosylation of QG to produce Q may have occurred by continuing cell incubation.

The in vivo activity of food components depends on their bioavailability. The ingested dietary flavonoids are subject to the gastrointestinal absorption. QG is efficiently absorbed despite possessing the glucose moiety. ${ }^{35)}$ The metabolic system for $\mathrm{Q}$ glycosides to be enzymatically deglycosylated suggests the possibility that QG shows in vivo almost the same functional significance as aglycone. ${ }^{36)} \mathrm{QG}$ is also deglycosylated by bacteria and shed epithelial cells in saliva. ${ }^{37)}$ Biotransformation in the oral cavity may be advantageous for QG to exhibit the anti-proliferative effect on oral cancer cells as well as Q. Although the gastrointestinal absorption of QD1 and QD-2 has been unknown, the hydrophobic property enabling them to interact with membrane lipids supports their potent bioavailability and in vivo activity.

In summary, the brownish scale of onion contains different flavonoids with the anti-proliferative activity, which is associated with the activity to interact with lipid bilayers and rigidify cell membranes.

Acknowledgements This study was partly supported by a grant from the San-Ei Gen Foundation for Food Chemical Research (to H. T.).

\section{REFERENCES}

1) Stavric, B. (1997) Chemopreventive agents in foods. In Functionality of Food Phytochemicals (Johns, T. and Romeo, J. T., Eds.), Plenum Press, New York, pp. 53-87.

2) Wargovich, M. J. (1997) Experimental evidence for cancer preventive elements in foods. Cancer Lett., 114, 11-17.

3) Surh, Y.-J. (1999) Molecular mechanisms of chemopreventive effects of selected dietary and medicinal phenolic substances. Mutat. Res., 428, 305-327.

4) Grunicke, H. H. (1991) The cell membrane as a target for cancer chemotherapy. Eur. J. Cancer, 27, 281-284.

5) Daoud, S. S. (1992) Cell membranes as targets for anti-cancer drug action. Anticancer Drugs, 3, 443453.

6) Shinitzky, M. (1984) Membrane fluidity in malignancy. Adversative and recuperative. Biochim Biophys. Acta, 738, 251-261.

7) Sherbet, G. V. (1989) Membrane fluidity and cancer metastasis. Exp. Cell Biol., 57, 198-205.

8) Taraboletti, G., Perin, L., Bottazzi, B., Mantovani, A., Giavazzi, R. and Salmona, M. (1989) Membrane fluidity affects tumor-cell motility, invasion and lung-colonizing potential. Int. J. Cancer., 44, 707713.

9) Clarke, R., Van Den Berg, H. W. and Murphy, R. F. (1990) Reduction of the membrane fluidity of human breast cancer cells by tamoxifen and $17 \beta$-estradiol. J. Natl. Cancer Inst., 82, 1702-1705.

10) Marutaka, M., Iwagaki, H., Suguri, T., Tanaka, N. and Orita, K. (1994) Alterations of membrane fluidity in K562 cells exposed to the anticancer drug adriamycin. Res. Commun. Mol. Pathol. Pharmacol., 85, 163-170.

11) Gaber, M. H., Ghannam, M. M., Ali, S. A. and Khalil, W. A. (1998) Interaction of doxorubicin with phospholipid monolayer and liposomes. Biophys. Chem., 70, 223-229.

12) Arora, A., Byrem, T. M., Nair, M. G. and Strasburg, G. M. (2000) Modulation of liposomal membrane fluidity by flavonoids and isoflavonoids. Arch. Biochem. Biophys., 373, 102-109.

13) Yu, J., Cheng, Y., Xie, L. and Zhang, R. (1999) Effects of genistein and daidzein on membrane characteristics of HCT cells. Nutr. Cancer, 33, 100-104.

14) Tsuchiya, H., Nagayama, M., Tanaka, T., Furusawa, M., Kashimata, M. and Takeuchi, H. (2002) Membrane-rigidifying effects of anti-cancer dietary factors. BioFactors, 16, 45-56.

15) Tsuchiya, H. and Nagayama, M. (2004) Interactions with bio-membranes and functionality of plant foodstuffs. FFI J. Jpn., 209, 820-833.

16) Formica, J. V. and Regelson, W. (1995) Review of the biology of quercetin and related bioflavonoids. Food Chem. Toxicol., 33, 1061-1080.

17) Shon, M.-Y., Choi, S.-D., Kahng, G.-G., Nam, S.H. and Sung, N.-J. (2004) Antimutagenic, antioxidant and free radical scavenging activity of ethyl 
acetate extracts from white, yellow and red onions. Food Chem. Toxicol., 42, 659-666.

18) Furusawa, M., Tanaka, T., Nakaya, K., Inuma, M. and Tsuchiya, H. (2002) A new flavonol glucoside from onion. Heterocycles, 57, 2175-2177.

19) Furusawa, M., Tsuchiya, H., Nagayama, M., Tanaka, T., Nakaya, K. and Iinuma, M. (2003) Anti-platelet and membrane-rigidifying flavonoids in brownish scale of onion. J. Health Sci., 49, 475-480.

20) Kitagawa, S., Orinaka, M. and Hirata, H. (1993) Depth-dependent change in membrane fluidity by phenolic compounds in bovine platelets and its relationship with their effects on aggregation and adenylate cyclase activity. Biochim. Biophys. Acta, 1179, 277-282.

21) Vlasic, N., Medow, M. S., Schwarz, S. M., Pritchard, K. A. Jr. and Stemerman, M. B. (1993) Lipid fluidity modulates platelet aggregation and agglutination in vitro. Life Sci., 53, 1053-1060.

22) Tsuchiya, H., Mizogami, M. and Takakura K. (2005) Reversed-phase liquid chromatographic retention and membrane activity relationships of local anesthetics. J. Chromatogr., A, 1073, 303-308.

23) Van Blitterswijk, W. J., De Veer, G., Krol, J. H. and Emmelot, P. (1982) Comparative lipid analysis of purified plasma membranes and shed extracellular membrane vesicles from normal murine thymocytes and leukemic GRSL cells. Biochim. Biophys. Acta, 688, 495-504.

24) Borst, J. W., Visser, N. V., Kouptsova, O. and Visser, A. J. W. G. (2000) Oxidation of unsaturated phospholipids in membrane bilayer mixtures is accompanied by membrane fluidity changes. Biochim. Biophys. Acta, 1487, 61-73.

25) Tilley, L., Thulborn, K. R. and Sawyer, W. H. (1979) An assessment of the fluidity gradient of the lipid bilayer as determined by a set of $n$-(9-anthroyloxy) fatty acids $(n=2,6,9,12,16)$. J. Biol. Chem., 254, 2592-2594.

26) Tsuchiya, H. (2001) Structure-specific membranefluidizing effect of propofol. Clin. Exp. Pharmacol. Physiol., 28, 292-299.

27) Sok, M., Sentjurc, M. and Schara, M. (1999) Membrane fluidity characteristics of human lung cancer. Cancer Lett., 139, 215-220.
28) Miccoli, L., Oudard, S., Beurdeley-Thomas, A., Dutrillaux, B. and Poupon, M.-F. (1999) Effect of 1-(2-chlorophenyl)- $N$-methyl- $N$-(1-methylpropyl)3-isoquinoline carboxamide (PK11195), a specific ligand of the peripheral benzodiazepine receptor, on the lipid fluidity of mitochondria in human glioma cells. Biochem. Pharmacol., 58, 715-721.

29) Ikezaki, K. and Black, K. L. (1990) Stimulation of cell growth and DNA synthesis by peripheral benzodiazepine. Cancer Lett., 49, 115-120.

30) Deliconstantinos, G. (1987) Physiological aspects of membrane lipid fluidity in malignancy. Anticancer Res., 7, 1011-1022.

31) Wiseman, H. (1994) Tamoxifen: new membrane-mediated mechanisms of action and therapeutic advances. Trends Pharmacol. Sci., 15, 83-89.

32) Singh, J. K., Dasgupta, A., Adayev, T., Shahmehdi, S. A., Hammond, D. and Banerjee, P. (1996) Apoptosis is associated with an increase in saturated fatty acid containing phospholipids in the neuronal cell line, HN2-5. Biochim. Biophys. Acta, 1304, 171178.

33) Mandlekar, S. and Kong, A.-N. T. (2001) Mechanisms of tamoxifen-induced apoptosis. Apoptosis, 6, 469-477.

34) Williamson, G., Plumb, G. W., Uda, Y., Price, K. R. and Rhodes, M. J. (1996) Dietary quercetin glycosides: antioxidant activity and induction of the anticarcinogenic phase II marker enzyme quinone reductase in Hepalclc7 cells. Carcinogenesis, 17, 2385-2387.

35) Hollman, P. C. H. and Katan, M. B. (1999) Dietary flavonoids: intake, health effects and bioavailability. Food Chem. Toxicol., 37, 937-942.

36) Day, A. J., DuPont, M. S., Ridley, S., Rhodes, M., Rhodes, M. J., Morgan, M. R. and Williamson, G. (1998) Deglycosylation of flavonoid and isoflavonoid glycosides by human small intestine and liver beta-glucosidase activity. FEBS Lett., 436, 71-75.

37) Walle, T., Browning, A. M., Steed, L. L., Reed, S. G. and Walle, U. K. (2005) Flavonoid glucosides are hydrolyzed and thus activated in the oral cavity in humans. J. Nutr., 135, 48-52. 